\title{
Synthesis and Physical Properties of
}

\section{Pentamethylmanganocene, $\left(\mathrm{C}_{5} \mathrm{Me}_{5}\right) \mathrm{Mn}\left(\mathrm{C}_{5} \mathrm{H}_{5}\right)$ and}

\section{the Inclusion Compounds $\left[\left(\mathrm{C}_{5} \mathrm{Me}_{5}\right)_{2} \mathrm{Yb}\right]_{2}\left[\left(\mathrm{C}_{5} \mathrm{H}_{5}\right)_{2} \mathrm{M}\right]$}

\section{(where $\mathrm{M}=\mathrm{V}, \mathrm{Cr}, \mathrm{Fe}, \mathrm{Co}$ )}

Marc D. Walter, ${ }^{\dagger}{ }^{\prime}$ Carol J. Burns, ${ }^{\dagger}$ Phillip T. Matsunaga,$^{\dagger}$ Michael E. Smith ${ }^{\dagger}$ and Richard A. Andersen ${ }^{*}$

${ }^{\dagger}$ Department of Chemistry and Chemical Sciences Division of Lawrence Berkeley National Laboratory, University of California, Berkeley, California 94720;

$\$$ Technische Universität Braunschweig, Institut für Anorganische und Analystische Chemie, Hagenring 30, 38106 Braunschweig

E-mail: raandersen@lbl.gov

Table of Content:

1. $\chi^{-1}$ and $\mu_{\text {eff }}$ vs. T plots for $\left(\mathrm{Cp}_{2}{ }_{2} \mathrm{Yb}\right)_{2}\left(\mathrm{Cp}_{2} \mathrm{Co}\right)$ and $\mathrm{Cp}_{2} \mathrm{Co} \quad \mathrm{S} 2$

2. $\delta$ vs. $\mathrm{T}^{-1}$ plot for $\mathrm{Cp}^{*} \mathrm{NiCp} \quad \mathrm{S} 2$

3. X-band EPR spectrum of $\mathrm{Cp} * \mathrm{CoCp} \quad$ S 3

4. $\mu_{\text {eff }}$ vs. $\mathrm{T}$ plots for $\mathrm{Cp} * \mathrm{MnCp}$ recorded in quartz tubes or KEL-F buckets $\quad$ S 3 
1. $\chi^{-1}$ and $\mu_{e f f} v s . T$ plots for $\left(C p_{2}^{*} Y b\right)_{2}\left(C p_{2} C o\right)$ and $C p_{2} C o$

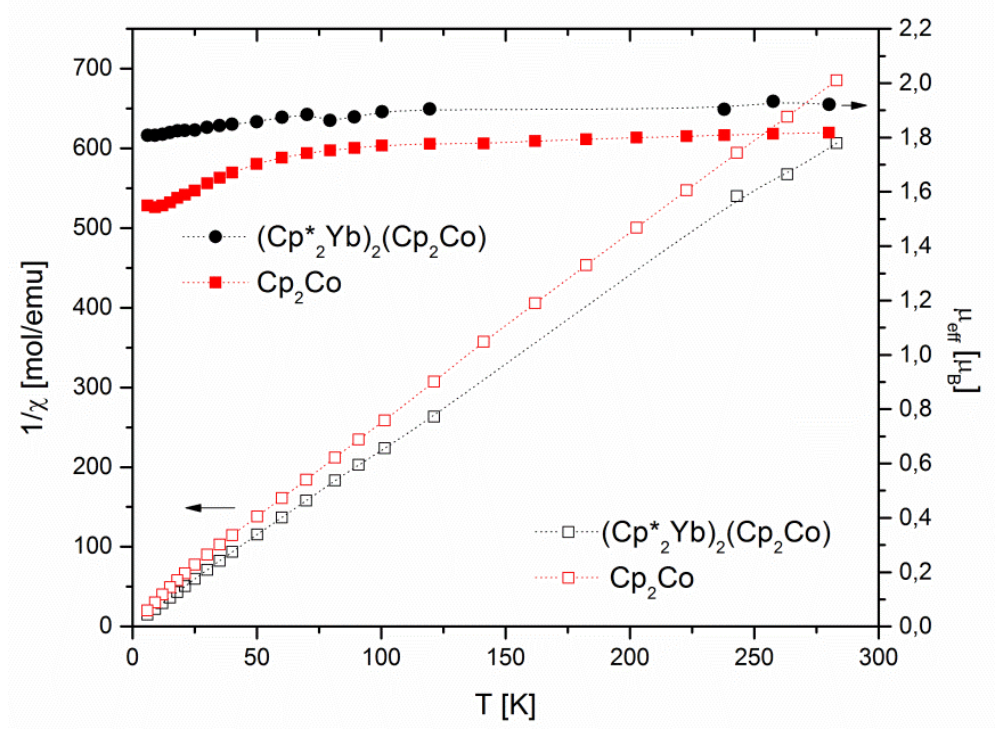

Figure S1. $\chi^{-1}$ and $\mu_{\text {eff }}$ vs. T plots for $\left(\mathrm{Cp}^{*}{ }_{2} \mathrm{Yb}\right)_{2}\left(\mathrm{Cp} \mathrm{p}_{2} \mathrm{Co}\right)$ and $\mathrm{Cp}_{2} \mathrm{Co}$ recorded between $5-280 \mathrm{~K}$ at $5 \mathrm{kG}$.

2. $\delta$ vs. $T^{l}$ plot for $\mathrm{Cp} * \mathrm{NiCp}$

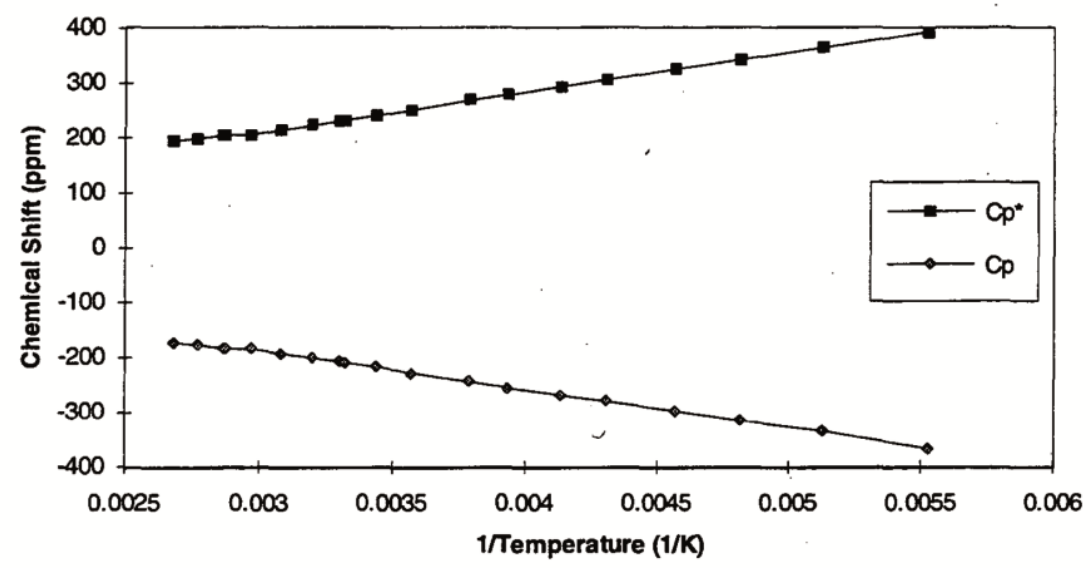

Figure S2. $\delta$ vs. $\mathrm{T}^{-1}$ plot for $\mathrm{Cp} * \mathrm{NiCp}$ recorded from $\mathrm{T}=-90$ to $+100{ }^{\circ} \mathrm{C}$ in $\mathrm{C}_{7} \mathrm{D}_{8}$. 


\section{X-band EPR spectrum for $\mathrm{Cp}{ }^{*} \mathrm{CoCp}$}

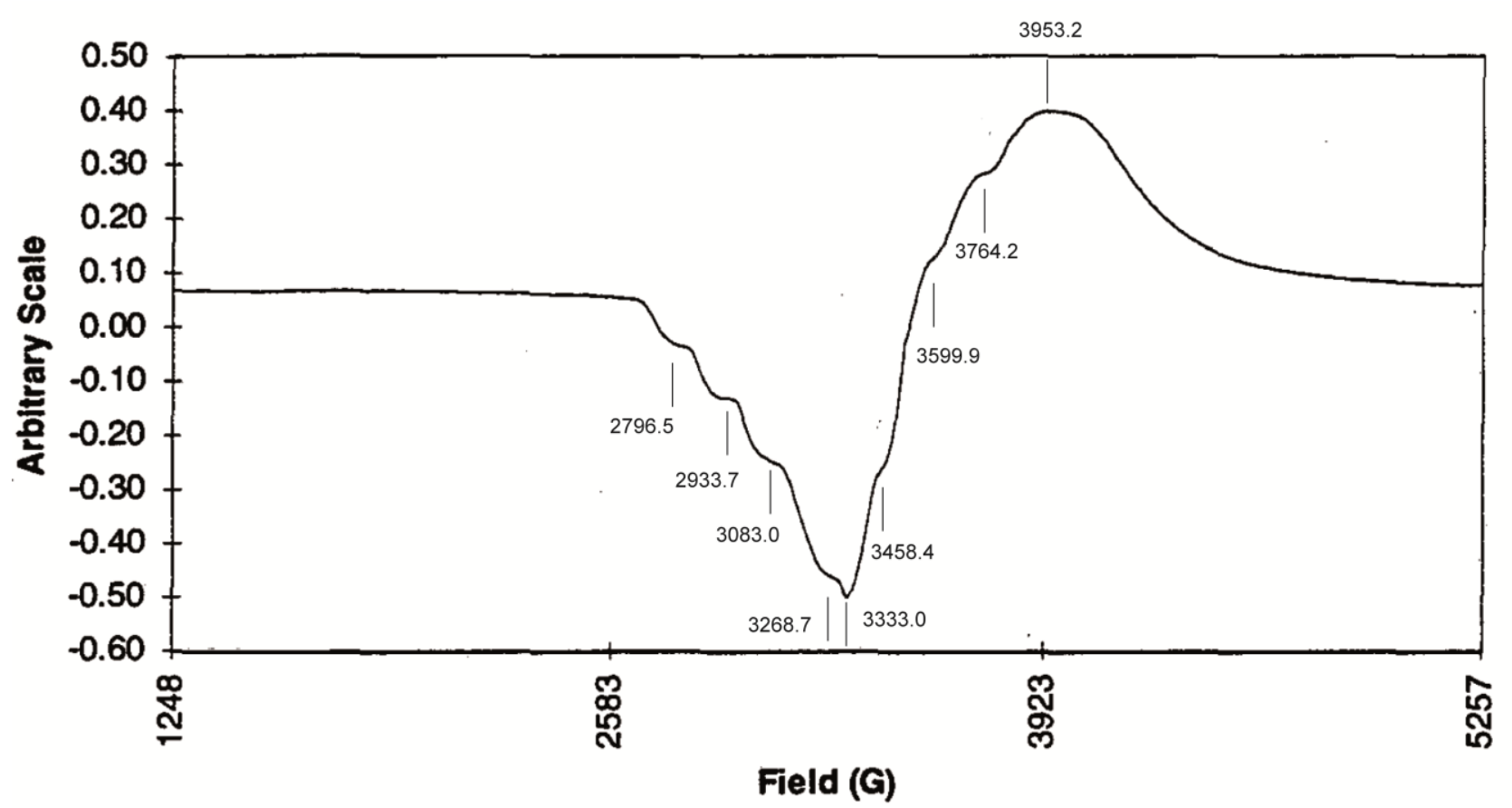

Figure S3. EPR spectrum of $\mathrm{Cp} * \mathrm{CoCp}$ recorded in frozen methylcyclohexane solution at $4.5 \mathrm{~K}$ $\left(\mathrm{g}_{\perp}=1.946, \mathrm{~A}_{\perp}=163.5 \mathrm{G}, \mathrm{g}_{\|}=1.818\right)$.

4. $\mu_{\text {eff }} v s . T$ plots for $C p * M n C p$ recorded in quartz tubes or KEL-F buckets

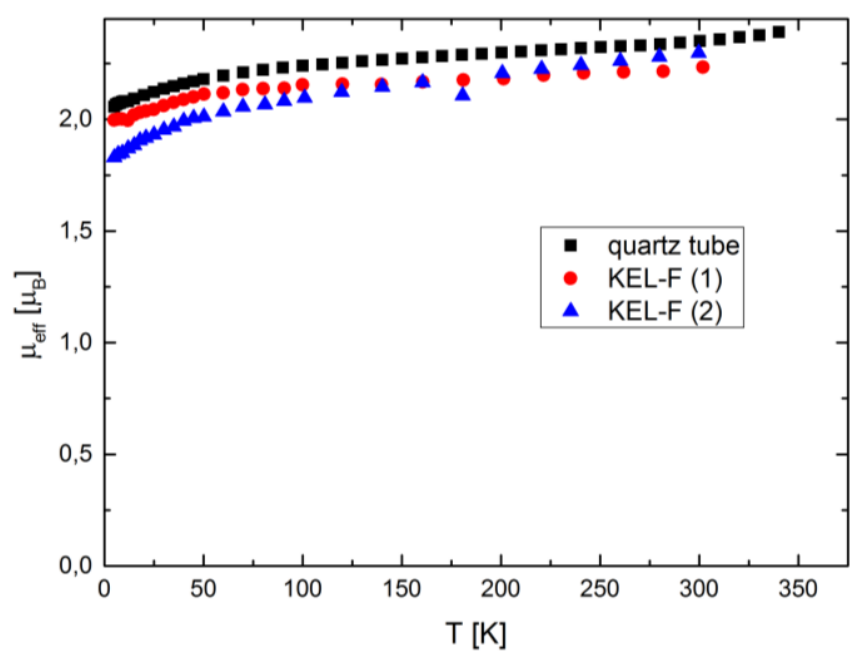

Figure S4. $\mu_{\text {eff }} v s$. T plots for $\mathrm{Cp} * \mathrm{MnCp}$ recorded in quartz tubes or KEL-F buckets at an applied field of $5 \mathrm{kG}$. 